\title{
Thou shalt not smoke: Content and context in the Lord's Resistance Army's concept of the Ten Commandments
}

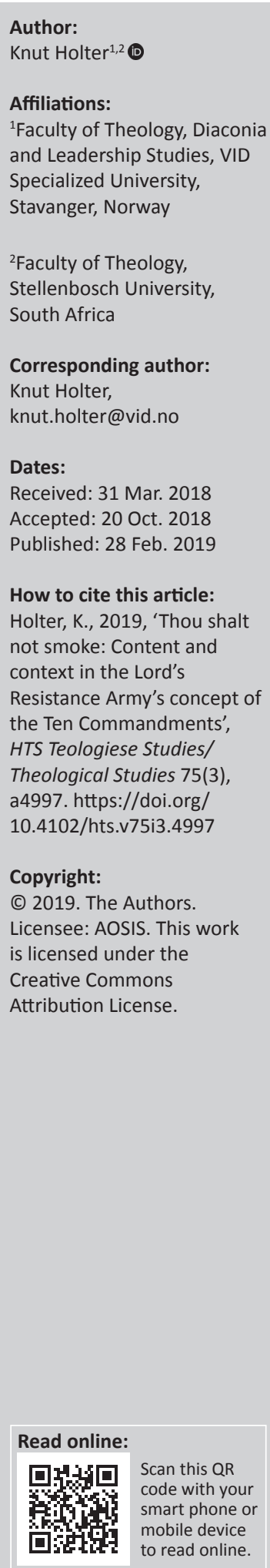

With the Ten Commandments as a case, the overall focus of this article is how a reader's a priori concept of a text influences how he or she allows textual content and interpretive context to interact. The frame of the article is the claim by the so-called Lord's Resistance Army (LRA) in Uganda that they will establish a society built on the Ten Commandments, a claim that raises questions about what they mean with this reference to 'Ten Commandments'. The article falls into two parts. The first part surveys some examples from the history of interpretation of the Ten Commandments, demonstrating contextual and terminological fluidity both in their biblical versions and in their postbiblical history of interpretation. With this insight, the second part discusses how LRA refers to the Ten Commandments in ways that demonstrate that the very concept 'Ten Commandments' is stronger than the details of their content. This enables the LRA to form 'new commandments' fitting with their ideology and struggle.

\section{Introduction}

The main title of this article is, of course, a construction. Its terminology and style, imitating the King James version of the Ten Commandments, are meant to lead the reader's imagination to this well-known classical text. At the same time, it is expected that a reader who is actually familiar with the Ten Commandments intuitively will search for an explanation of the surprising verb 'smoke' at the end of the supposed commandment. Then, we are at the centre of the article: How does a reader's a priori concept of the Ten Commandments influence how he or she allows textual content and interpretive context to interact?

The interpretive context of this constructed commandment is the Lord's Resistance Army (LRA), a guerilla group in northern Uganda supposedly aiming to take control of the country and rule it according to the Ten Commandments. ${ }^{1}$ I will return to the LRA and this interpretive context of theirs vis-à-vis the Ten Commandments later in this article. However, before that, I will discuss some more general aspects of the interaction between textual content and interpretive context with regard to the Ten Commandments.

\section{Biblical expressions and postbiblical reception}

Already from the very beginning, that is, in the biblical texts themselves, there is some ambiguity with regard to the concept, content and context of the Ten Commandments (Weinfeld 1991:242267). The very expression 'Ten Commandments', or rather 'ten words', is found only three times in the Old Testament and the Bible as a whole. According to Exodus 34:27-28, Moses is requested to write down 'these words', and he does so: he writes down 'the words of the covenant, the ten words' on (according to v. 29: two) tablets. The expression 'ten words' is accordingly linked to a 'covenant', but the details of their content are not clarified. Textually speaking, 'these words' in v. 27 seem to refer to the preceding list of rules in verses 11-26, often referred to as the Ritual Decalogue, and the connection between the 'ten words' in verse 28 and the Ten Commandments in Exodus 20:1-17 is unclear. The two other cases where the expression 'ten words' occurs are Deuteronomy 4:13 and 10:4; the former refers to 'ten words' written on two tablets in the context

The fieldwork material referred to in the second part of this article is taken from a PhD thesis by Dr Helen Nambalirwa Nkabala Makerere University, Uganda (cf. Nkabala 2012), a thesis project that was part of a larger research project at the School of Mission and Theology (now part of VID Specialized University) in Stavanger, Norway, on reintegration into society of female child soldiers in northern Uganda (cf. Mæland 2010). Nkabala's project was licensed by the Norwegian Social Science Data Services and the National Council of Higher Education in Uganda, and she has elsewhere published some of her findings (cf. Nkabala 2010, 2013, 2014). I had the pleasure of being part of the larger project (cf. Holter 2010) and also supervising Nkabala's thesis, and she has generously allowed me to use some quotes from her informants. Nevertheless, Nkabala should not be blamed for the present interpretation of these quotes, which is entirely mine.

Note: The collection entitled 'Eben Scheffler Festschrift', sub-edited by Jurie H. le Roux (University of Pretoria) and Christo Lombaard (University of South Africa). 
of a 'covenant' whereas the latter lacks the reference to the 'covenant'. In other words, the expression 'ten words' - or 'Ten Commandments', as it has become known in the history of its interpretation - seems to refer to a fixed concept of covenant and tablets, but the details of its content are not that clear.

Not surprisingly, therefore, the two Pentateuch versions of what are usually identified as the 'Ten Commandments', that is, the lists in Exodus 20:1-17 and Deuteronomy 5:6-21, are not exactly similar. As any observant reader of the Pentateuch will have noticed, there are certain differences between the laws of Deuteronomy and previous - textually speaking, in Exodus through Numbers - versions of the same or similar laws (Levinson 1997). One would therefore expect the same to be the case with regard to the Exodus 20 and Deuteronomy 5 versions of the Ten Commandments as well, and indeed it is. Biblical scholars who have compared the two versions have been able to identify a number of differences, stretching from that of a single letter to that of several sentences (Hossfeld 1982:21-162). For pragmatic reasons - illustrative differences in the two Old Testament versions as well as different postbiblical interpretive traditions - I will restrict myself to three cases: the Sabbath commandment, the commandment against making images and the Samaritan version of the last commandments.

Firstly, the Sabbath commandment is probably the most visible example of a difference between the Exodus 20 and Deuteronomy 5 versions of the Ten Commandments. One thing is the different verbs used to express the keeping of the Sabbath; Exodus 20:8 says 'remember', whereas Deuteronomy 5:12 sharpens it to 'observe', probably reflecting Deuteronomy's general sharpening of the legislation. More striking, though, is the different theologising used to justify the commandment. On the one hand, Exodus 20:11 points to creation: 'for in six days the Lord made the heavens and the earth, the sea, and all that is in them, but he rested on the seventh day'. On the other hand, Deuteronomy 5:15 points to the liberation from Egypt: 'Remember that you were slaves in Egypt and that the Lord your God brought you out of there with a mighty hand and an outstretched arm'. The Exodus 20 version is close to the Priestly layer of the Pentateuch (cf. Gn 2:2-3), whereas the Deuteronomy 5 version can find close material elsewhere in Deuteronomy (cf. 15:15 and 16:12). The interpretive role of the difference cannot be solved here; therefore, we will simply have to acknowledge that this particular commandment - and the Ten Commandments as a whole - at the time of the final composition of the Pentateuch was still a somewhat fluid entity, where different interpretive contexts could express different interpretive strategies.

Secondly, the commandment against making images contains a far less striking example of a difference between Exodus 20 and Deuteronomy 5. It is actually a question of one single letter, a copulative waw (cf. Holter 2003:72-77). On the one hand, Deuteronomy 5:8 has an asyndetic coordination between 'image' and the following 'the form of anything', whereas Exodus 20:4 has a syndetic coordination, introducing a copulative waw: 'an image and the form of anything'. It could be argued that this tiny difference is related to the pronoun 'them' later in the commandment (Ex 20:5; Dt 5:9). In the syndetic Exodus version, the prohibition of worshipping 'them' refers to the preceding plural 'an image and the form of anything', whereas in the asyndetic Deuteronomy version, the plural 'them' points over the singular 'an image, the form of anything' and back to the plural 'other gods' in the previous commandment (Hossfeld 1982:21-26). The differences probably reflect different interpretive strategies and contexts, allowing the Deuteronomy version of the commandment to link the prohibition against images closely to the prohibition of 'other gods', and the Exodus version to give the commandment against images a more independent role.

Thirdly, the Samaritan version of the Ten Commandments adds a strikingly long passage after Exodus 20:17, as an additional tenth commandment. The passage is derived from Deuteronomy 11:29-30 and 27:2b-3a.4-7, and it commands the Israelites to erect an altar on Mount Gerizim. This particular tenth commandment is part of a layer of expansions in the Samaritan Pentateuch, and it reflects and expresses the key role of Mount Gerizim - rather than Jerusalem and its temple - in Samaritan theology (cf. Kartveit 2009:290-295). The practical problem of still having Ten Commandments only is solved by counting Exodus 20:3-6 (no other gods and no graven image) as the first commandment and 20:17 (as a whole) as the ninth. The Samaritan strategy offers a vivid exemplification of how the concept of 'ten' commandments survives the inclusion of an additional one, and it demonstrates that this concept of 'ten' is more important than the actual details of the ten, at least when it is a question of adding a text that expresses a key theological perspective in that particular interpretive context.

The major postbiblical reception communities of the Ten Commandments - the synagogue and the church - allow the Ten Commandments to play major roles in theology as well as liturgy. This is not the place to go into the details of these receptions; let me restrict myself to some brief comments to the same three commandments as I discussed above, and again, use these as examples of how the concept of Ten Commandments and the content of the individual commandments negotiate with their interpretive contexts.

Firstly, as for the Sabbath commandment, there was an early split between the synagogue and the church, whereas the commandment continued to play an important role throughout the centuries in Rabbinic Judaism (Levinson 1987:80-83), Christianity transferred it from Saturday to Sunday and its celebration of the 'first day of the week' (Ac 20:7; 1 Cor 16:2). The point of the day is then to be a commemoration of the resurrection of Jesus, rather than Exodus 20's focus on creation or Deuteronomy 5's focus on 
the liberation from Egypt. This transfer is an interesting example of how a new theological context led to a new rationale of an already existing commandment. Nevertheless, some of the basic characteristics of the Sabbath continued; it was still a day for rest (not only for 'you', but also for servants and foreigners) and a day set aside as 'holy' (with the main worship service of the week).

Secondly, the reception history of the commandment against images reflects concerns of its different interpretive contexts. From early times, the Jewish tradition was and has continued to be quite restrictive with regard to the use of images in the cultic life, whereas the Christian tradition differs more and is able to come up with a broad range of theological interpretations and artistic concretisations. On the one hand, the Roman Catholic tradition - followed, for example, by the Lutherans - allows images by referring to the incarnation: God became incarnate in the person of Jesus, whom the first Christians said that they had seen with their eyes and touched with their hands (cf. 1 Jn 1:1), and can therefore be portrayed artistically. On the other hand, the Orthodox tradition distinguishes between icons and images, allowing the former and rejecting the latter, whereas churches of the Reformed tradition normally reject all kinds of images. In my own Lutheran tradition, there are many church buildings with the text of the Ten Commandments displayed on the wall, but then not in their Exodus 20 or Deuteronomy 5 versions, rather according to Luther's Small Catechism, where the Commandment against images simply is left out, and where Exodus 20:17 and Deuteronomy 5:21 are counted as two independent commandments to preserve the concept of 'ten'.

Thirdly, the Samaritan commandment about Mount Gerizim has over the centuries been a crucial expression of the theology and cultic life of the small Samaritan community, traditionally located around Nablus. But the idea itself has been kept alive outside the Samaritan community because of the New Testament narrative about Jesus and a Samaritan woman. According to John 4:20, she invited Jesus to a dialogue exactly about where the right place of worshipping is: 'Our ancestors worshipped on this mountain, but you Jews claim that the place where we must worship is in Jerusalem'.

Summing up so far, we have observed examples of some fluidity with regard to the text of the Ten Commandments. The text can be expanded (see the Samaritan version and its commandment about building an alter at Mount Garizim) and reduced (see the interpretive history of the commandment against making images), and the individual commandments can both be remotivated (see the Sabbath commandment, first with the relationship between Exodus 20 and Deuteronomy 5, and then in its Christian reception) and reformulated (see the terminological differences between the introductions of the same two commandments, and see also the different theological accents of the syndetic Exodus 20:4 and asyndetic Deuteronomy 5:8 versions of the commandment against making images).

\section{Experiences from Bible and reception in dialogue with Lord's Resistance Army concepts}

As discussed above, the LRA was - and to a minor extent still is - a guerilla group in northern Uganda. The group grew out of the turbulent situation in Uganda in the 1980s and 1990s, with various guerilla groups, often using religion as a means of interpreting the situation and legitimising their particular cause (cf. Behrend 1999). Under the leadership of Joseph Kony, the LRA was during the last decade of the 20th century and the first decade of the 21st century, a dominating factor in Acholiland in northern Uganda, notoriously famous for its abduction of children for purposes of serving as child soldiers or sex slaves (Cline 2013:57-74).

In spite of a reputation of violence and evil, Kony and the other LRA leaders continuously claimed that their aim was to rule Uganda in accordance with the Ten Commandments (De Temmerman 2001:15, 23, 70, 156). Although it can be argued that this claim mainly has an internal function, legitimising the LRA atrocities vis-à-vis the more ordinary guerilla fighters and not least the abducted children, it seems that the idea of the Ten Commandments as a rationale underneath the struggle has played an important role over many years.

In a PhD thesis on religious rhetorics in the LRA, Dr Helen Nambalirwa Nkabala (currently at Makerere University, Kampala) has analysed LRA's use of the Old Testament, thereby locating the LRA's focus on the Ten Commandments in a larger textual and interpretive context. One of Nkabala's findings is that official LRA representatives as well as former abductees seem to conceptualise Joseph Kony as a kind of parallel to Moses. In the words of one of her informants:

There is no difference between Moses and Kony. The way the history tells about Moses to me it looks similar to what Joseph is doing. (Nkabala 2012:70)

Within the LRA, Kony is accordingly portrayed in correspondence with the Old Testament characteristics of Moses. Partly, he is a liberator; while Moses liberated Israel from Pharaoh, Kony will liberate the Acholi people from the regime of President Museveni. Partly, he is also a prophet; while Moses had God's confidence and knew the destiny of his people, Kony can foresee what is going to happen in the battlefield. And partly, he is even a lawgiver; while Moses was the mediator of the Ten Commandments to his people, Kony mediates instructions from God into the LRA context (cf. Nkabala 2012:70-97). In Nkabala's (2012) words:

Just as Moses was responsible for giving the Ten Commandments to the Israelites, it is believed that Joseph Kony receives instructions from God, which Kony then passes on to the LRA followers. The followers then fight with the aim of ensuring that people do not break the Ten Commandments of the Old Testament. (p. 76)

Kony's role as a lawgiver does not mean only repeating existing laws, such as the Ten Commandments. 
Being chosen as an instrument of God, Kony can also reveal new commandments. In the words of one of Nkabala's (2012) informants:

When the spirit comes on Kony at a particular time, then he begins giving instructions to commanders. When Kony was still seriously possessed by the spirit, he would call us and preach. After that he would say that now it is time to recite the Ten Commandments. But instead of everybody reciting, we would keep quiet and look at Kony. Then the spirit would descend upon Kony in a white form, and after that Kony would say that the spirit has given us the following instructions and these are the commandments. So whenever the spirit comes, we get new commandments. (p. 78)

Another informant confirms this:

The Ten Commandments which are in the Bible are not those of the LRA, but they are instructions or what Kony calls his commandments. He gets them [from the spirit] and passes them on, instructing what soldiers should do. (Nkabala 2012:79)

This does not mean that the 'Ten Commandments' of the LRA and Joseph Kony are completely different from the Ten Commandments in the Pentateuch; Nkabala is eager to point out that they are influenced by the biblical ones, like not having other gods, keeping the Sunday, not stealing or killing, not committing adultery and so forth. Nevertheless, as far as I can judge, what it means is that the concept of 'Ten Commandments' lives a life somewhat independent of their Exodus 20 and Deuteronomy 5 versions. Referring to the 'Ten Commandments' allows the LRA and Kony to make use of a concept that is already known and has a high position in the interpretive context of his audience. But then, at the same time, and at least to some extent, Kony and the other leaders of the LRA see the potential of filling this already well-known concept with new content, according to their particular ideology and practical needs.

What are then the 'new' commandments that are presented and linked to the concept of 'Ten Commandments'? One is a prohibition against smoking, as indicated in the title of this article. The interpretive context of this commandment is the LRA fighters who are hiding from government troops out in the battlefield. Some of Nkabala's informants would tell her that they were able to smell the government troops, because these troops were allowed to smoke, or, for that matter, because they were allowed to use body lotion (Nkabala 2012:86, 158). To avoid such a security problem and at the same time have the strategic advantage of surprising the enemy, Kony forbade - in the form of a commandment - his men from smoking, or using body lotion. Another 'new' commandment is a prohibition against cycling. Again, the interpretive context is the situation out in the battlefield. A bike can, of course, be used to escape, assumably a temptation for guerilla fighters who have been abducted and forced into service of the LRA. And again, Kony responds to a potentially threatening situation with an instruction in the form of a commandment.
In other words, the content of the 'new' commandments grows out of their immediate interpretive context: in order not to be discovered by the enemy, 'you' should not smoke or use body lotion, and in order to prevent the guerilla troops from deserting, 'you' should not have a bike. However, this immediate interpretive context of theirs does not include the practical circumstances in the battlefield alone - even more important is that it also includes the cultural and religious background of the fighters. And it is here that the concept of the 'Ten Commandments' belongs. Kony and the other LRA leaders could use the concept of 'Ten Commandments' to secure their own power simply because the concept was already known and had a high position amongst those recruited into the LRA. The fact that the concept itself was more known and more important than the actual content of the biblical versions of the commandments was what made it possible for the LRA to use it to justify their ideology and struggle.

\section{Conclusion}

So, how does a reader's a priori concept of the Ten Commandments influence how he or she allows textual content and interpretive context to interact? In the case of the LRA, the concept of 'Ten Commandments' is more important than the details of the content of the individual commandments. This opens up for an introduction of new expressions of God's ethical requests, constructed in the form of the well-known and well-respected 'Ten Commandments'.

What can we learn from this? The parallels between the LRA's concerns and use of the Ten Commandments and certain more general lines in the interpretive history of the commandments can be used analytically in two different directions. On the one hand, the more general lines can serve as an analytical key to comprehend the LRA's concerns and use of the same. We may understand what the LRA is doing with the Ten Commandments, simply because we have seen it - or at least some of it, though not necessarily that extreme - before. Throughout its history of interpretation, the Ten Commandments have been dialoguing with various contextual concerns, and it has been used for legitimising various contextual purposes. On the other hand, the LRA's concerns and use of the Ten Commandments can serve as an analytical key to comprehend more general lines in the interpretive history of the concept and content of the same. With the LRA, we have a contemporary illustration of how the concept of the Ten Commandments and the content of these commandments are reshaped in dialogue with a particular interpretive context.

\section{Acknowledgements Competing interests}

The author declares that he has no financial or personal relationships which may have inappropriately influenced him in writing this article. 


\section{References}

Behrend, H., 1999, Alice Lakwena \& the Holy Spirits: War in Northern Uganda 1986-97, James Currey, Oxford. (Eastern African Studies).

Cline, L.E., 2013, The Lord's Resistance Army, Praeger, Santa Barbara.

Holter, K., 2003, Deuteronomy 4 and the Second Commandment, Peter Lang, New York. (Studies in Biblical Literature, 60).

Holter, K., 2010, 'Women and war in northern Uganda and ancient Israel: The interpretative role of academia', in B. Mæland (ed.), Culture, religion, and the reintegration of female child soldiers in Northern Uganda, pp. 207-218, Peter Lang, New York. (Bible and Theology in Africa, 10).

Hossfeld, F.-L., 1982, Der Dekalog: Seine späten Fassungen, die originale Komposition und seine Vorstufen, Universitätsverlag Freiburg Schweiz, Freiburg. (Orbis Biblicus und Orientalis, 45).

Kartveit, M., 2009, The origin of the Samaritans, Brill, Leiden. (Supplements to Vetus Testamentum, 128).

Levinson, B.M., 1997, Deuteronomy and the hermeneutics of legal innovation, Oxford University Press, New York.

Levinson, P.N., 1987, Einführung in die rabbinische Theologie, Wissenschaftliche Gesellschaft, Darmstadt.
Mæland, B., (ed.), 2010, Culture, religion, and the reintegration of female child soldiers in Northern Uganda, Peter Lang, New York. (Bible and Theology in Africa, 10).

Nkabala, N.H., 2010, "'The Lord destroyed the cities and everyone who lived in them:" The Lord's Resistance Army's use of the Old Testament Sodom/Gomorrah narrative', in B. Mæland (ed.), Culture, religion, and the reintegration of female child soldiers in Northern Uganda, pp. 181-192, Peter Lang, New York. (Bible and Theology in Africa, 10).

Nkabala, H.N., 2012, "There is no difference between Moses and Kony": A critical analysis of the contextual use of some Old Testament texts and motifs in the early years of the Lord's Resistance Army', Unpublished PhD thesis, School of Mission years of the Lord's Resistance Army',
and Theology, Stavanger, Norway.

Nkabala, N.H., 2013, 'A gender-sensitive ethical reading of Old Testament texts: The role of African women as characters in the text and exponents of the text', Old Testament Essays 26, 384-400.

Nkabala, H.N., 2014, 'Gender perspectives in the Lord's Resistance Army in relation to the Old Testament', Old Testament Essays 27, 930-944.

De Temmerman, E., 2001, Aboke Girls: Children abducted in Northern Uganda, Fountain Publishers, Kampala.

Weinfeld, M., 1991, Deuteronomy 1-11, Doubleday, New York. (Anchor Bible, 5). 